\title{
|||||||||||||||||||||||||||||||||||||||||||||||||||||||||||||||||||.
}

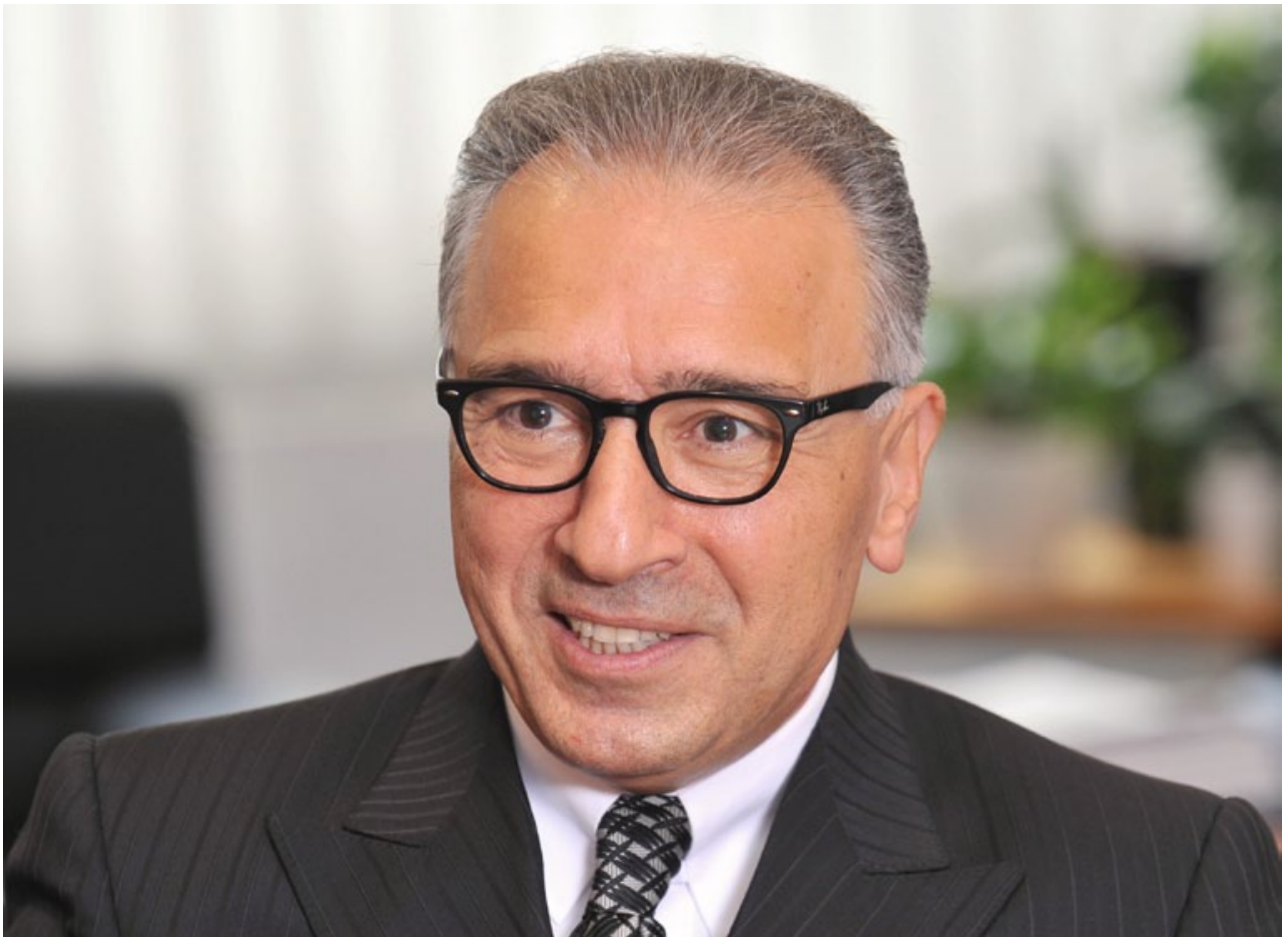

PROF. DR.-ING. FERIT KÜÇÜKAY

Leiter des Instituts für Fahrzeug technik, Technische Universität

Braunschweig

\section{ENERGIEVERBRAUCH IM VISIER}

Der Energieverbrauch des Automobils im Betrieb, also der „Tank-to-Wheel-Verbrauch“ (TtW), stellt intensiver denn je den Gegenstand der Forschung und Entwicklung am Automobil dar. Das Ziel dabei besteht in der Minimierung der Fahrwiderstände und der Maximierung des Wirkungsgrads des Antriebs und der Nebenverbraucher.

Bei Vernachlässigung der Nebenverbraucher, die im NEFZ praktisch keine Rolle spielen, wirken sich die Maßnahmen zur Reduzierung der Fahrwiderstände, wie zum Beispiel durch Leichtbau und Aerodynamik, auf den Gesamtenergieverbrauch direkt aus. Das bedeutet, dass etwa eine Verbesserung des Gesamtfahrwiderstands um 10 \% zu einer Verbrauchsverbesserung von ebenfalls $10 \%$ führt. Bei identischer Fahrzeugmasse gilt dieser Zusammenhang unabhängig von dem Antriebskonzept. Im theoretischen Grenzfall ist der TtW-Verbrauch Null, wenn die Fahrwiderstände Null sind. Die Konstruktion „fahrwiderstandsarmer" Fahrzeuge lohnt sich also immer.

Den Energiebedarf zur Überwindung der Fahrwiderstände deckt der Antrieb ab, der aus Energiewandler(n) und Kraftübertragung durch Getriebe und Triebstrang zwischen Energiespeicher und Antriebsrädern besteht. Während der Wandlung und der Übertragung der Energie zu den Rädern entstehen Verluste. Der auf den NEFZ bezogene durchschnittliche Wirkungsgrad des konventionellen Antriebs, der nach dem nun mehr abgeklungenen Hype um die Elektromobilität inten- siver in den Fokus gerückt ist, liegt häufig bei etwa $20 \%$. Dies bedeutet, dass der TtW-Verbrauch das Fünffache des Energiebedarfs zur Überwindung der Fahrwiderstände beträgt. Es gilt somit, die $20 \%$ zu verbessern, um dem als Benchmark anzusehenden Wirkungsgrad des E-Antriebs im NEFZ von circa $70 \%$ näher zu kommen. Denn, eine Verbesserung des durchschnittlichen Antriebswirkungsgrads etwa um 2-\%-Punkte, also von 20 auf $22 \%$, führt zu einer beachtlichen Verbrauchsreduzierung von $10 \%$.

Interessant ist dabei die Vielfalt der Lösungsvorschläge der Antriebsentwickler, die zuletzt im Dezember vergangenen Jahres anlässlich des 11. Internationalen CTI-Symposiums „Innovative Fahrzeuggetriebe, Hybrid- und Elektroantriebe“ in Berlin präsentiert wurden: Von Aktivgetrieben mit optimiertem inneren Wirkungsgrad und angepassten Gangstufen bis hin zu Detaillösungen lassen sich in der Summe Verbesserungen des Antriebswirkungsgrads von 5 bis 8 Prozentpunkten erreichen. Somit ergibt sich im TtW-Verbrauch eine Reduzierung von 25 bis $40 \%$ - und dies zu vertretbaren Kosten.

Gefragt sind also harmonierende Fahrzeug- und Antriebskonzepte, die sowohl zur Reduzierung der Fahrwiderstände als auch der Verbesserung des Antriebswirkungsgrads dienen. Detaillösungen, mögen sie einen noch so kleinen Beitrag liefern, dürfen auf dem Weg hin zu verbrauchsarmen Fahrzeugkonzepten nicht unberücksichtigt bleiben. 